\title{
Catalytic Process in Producing Green Aromatics through Fast Pyrolysis of Wood of Five Tropical Fast Growing Trees Species
}

\author{
Joko Sulistyo, Toshimitsu Hata, Ganis Lukmandaru, Yunida Syafriani, and Sensho Honma
}

\begin{abstract}
The generation of liquid fuels and chemicals is potential through a catalytic fast pyrolysis (CFP) which is a rapid, inexpensive, and promising method utilizing tropical wood biomass as starting material. There is a little known in the potential of wood biomass from tropical fast-growing trees as starting materials for the production of liquid fuel and chemicals. The pyrolysis of five species (balsa, eucalyptus, jabon, mangium, and sengon) was performed with a single-shot mode pyrolyzer. In this study the formation of aromatics by pyrolytic-gas chromatography/mass spectroscopy (Py-GC/MS) is evaluated on the effect of wood species with different characteristics and its cellulose component to the formation of aromatics. ZSM- 5 zeolite catalyst was used to evaluate aromatic production on balsa and ecualyptus samples. Fast pyrolysis of eucalyptus wood characterized with low content of ash and high percentages of hollocellulose and a-cellulose produced much high relative peaks of levoglucosan and small relative peaks of lignin derived products. Meanwhile high content of vollatile matter and high crystallinity of cellulose attributed balsa and jabon woods as feedstock for fast pyrolysis. The catalytic process in fast pyrolysis of eucalyptus decomposed the most of oxygenated compound such as levoglucosan and furfural into aromatics in the presence of ZSM-5. Coke formation on the surface catalyst might lead partly of decomposition of levoglucosan and furfural to form aromatics in the catalytic fast pyrolysis of balsa wood. Cellulose component was determined on the formation of benzene, toluene, styrene, p-xylene, indane, indene, and naphthalene in catalytic fast pyrolysis of wood.
\end{abstract}

Keywords: aromatics, catalytic fast pyrolysis, Py-GC/MS, wood characteristics, ZSM-5 catalyst.

\section{Introduction}

The production of fuels and chemicals from renewable resources is currently generating new interest. In contrast to fossil fuels, the use of renewable resources such as biomass for energy provides significant environmental advantages. Woody biomass which is available in a large amount in many parts of the world especially in tropical area is potential starting materials for liquid fuel and chemicals. One of the woody biomass sources is from the harvesting of industrial plantation and community forests which is mainly composed of fast-growing tree species. Renewable biomass has the potential to generate inexpensive fuels and organic chemicals if they are efficiently converted via an appropriate processing route. Therefore, clean energy development could turn away from fossil fuel towards regenerative energy sources such as wood biomass.

Fast pyrolysis thermal decomposition of biomass feedstock using a relatively high heating rate can yield liquids of up to $70 \sim 75 \%$ of the weight of the starting material (Gurgens et al. 2014). The crude pyrolysis liquid product is potential energy product because of its high energy density (Bridgwater 1996). However, the pyrolytic oil product requires full deoxygenation which can be accomplished by hydro-treating and catalytic vapor cracking (Czernik and Bridgwater 2004) and also by catalytic upgrading (Vitolo et al. 2001) to obtain a conventional transport fuels. Carlson et al. (2009) have developed a single step catalytic fast pyrolysis to produce aromatics including benzene, toluene, and naphthalene from biomass in a single reactor with a short residence time. The aromatic production and selectivity are found as a function of catalyst to feedstock weight ratio, heating rate, and reaction temperature (Carlson et al. 2010). French and Czernik (2010) performed a study on the efficiency of various catalyst for aromatic production and found that the highest yield of aromatics from wood, around $16 \mathrm{wt} \%$ including $3.5 \mathrm{wt} \%$ of toluene were obtained by ZSM-5 zeolite catalyst. Mihalcik et al. (2011) screened acidic zeolites for catalytic fast pyrolysis of biomass and its components and found that H-ZSM-5 zeolite lead to an increased production of aromatic hydrocarbons. Besides improving the quality of bio oil, impregnation of $10 \mathrm{wt} \% \mathrm{Fe}$ to ZSM-5 can increase in the amount of phenolic compound, aromatic and aliphatic hydrocarbon (Saracoglu et al. 2017).

There is less study on the development of liquid fuel and aromatics production through the catalytic fast pyrolysis utilizing wood biomass from tropical fast growing trees as starting material. In a previous study, it was found that aromatics including benzene, toluene, styrene, naphthalenes, and indanes were formed by a catalytic fast pyrolysis of red meranti (Shorea leprosula) biomass (Sulistyo et al. 2013). Since there are many fast-growing trees available in tropical area with different characteristics of wood, so selection of the potential woody biomass and cellulose component as starting material is useful. The objective of the study is to use Py-GC/MS to evaluate five tropical wood species and their cellulose components against ZSM- 5 catalysts to determine relative abilities to deoxygenated pyrolytic condensable components and produce aromatics. 


\section{Materials and Methods}

A wood disc sample was collected from the bottom part of trees of jabon (Antocephalus cadamba), sengon (Paraserianthes mollucana), and balsa (Ochroma sp) grown in community forest managed by PT. Partawood in Probolinggo - East Java Province, Indonesia. The present study used three trees for each wood species. Two other wood species i.e. mangium (Acacia mangium) and eucalyptus (Eucalyptus pellita) grown in Wanagama experimental forest of Universitas Gadjah Mada in Gunung Kidul District - Yogyakarta were used without replication. Part of the wood disc sample was milled into powder and sieved with wire mesh screens to obtain particles with size range of $0.25 \sim 0.42 \mathrm{~mm}$ (passing through 40 mesh sieve and retained by 60 mesh sieve). ZSM- 5 catalyst (Zeolyst International, CVB 3024E, nominal cation form: ammonium) was used in this study.

The moisture and volatile contents were determined by a gravimetric method according to ASTM D2867-17 and D1762-64, respectively. For moisture content, the sample was heated at $105^{\circ} \mathrm{C}$ for $2 \mathrm{~h}$ in the oven. The sample for volatile matter was heated to $950{ }^{\circ} \mathrm{C}$ for $7 \mathrm{~min}$ in muffle furnace. The ash content was obtained by heating the samples at $600{ }^{\circ} \mathrm{C}$ for $1 \mathrm{~h}$ in air to constant weight in muffle furnace according to ASTM D2866-94, the fixed carbon content was estimated by difference as follows :

Fixed carbon content $(\%)=[100-(\%$ ash content $+\%$ volatile matter content)]

For determining of holocellulose and a-cellulose contents, wood powder equal to dry weight of $2 \mathrm{~g}$ was determined according to chlorite acid method (Browning 1967) and ASTM D1103-60, respectively. The hemicellulose content was determined by substraction. Extractive soluble in alcohol-toluene was determined according to ASTM D1107-96. The crystallinity level of the wood sawdust were measured with an X-ray diffractometer (Shimadzu MAXima XRD 7000) for wide angle X-Ray Difraction (XRD). The equipment settings were $40 \mathrm{~mA}$ and $30 \mathrm{kV}$ with a $\mathrm{Cu} \mathrm{Ka}_{\mathrm{a}}$ radiation wavelength of $1.54 \AA$. The receiving slits were 0.3 $\mathrm{mm}$, and the intensity was measured as a function of the scattering angle $2 \theta$ by $\theta-2 \theta$ scan. The angle range was $10-$ 40 degrees and the step was 0.02 degree. The measuring time was chosen so the maximum intensity was about 84 counts, and it was typically 0.60 s per point. The crystallinity profiles of the wood sawdust are explained in terms of wood sawdust content. Crystallinity Index $(\mathrm{Cl})$ is calculated as the ratio between the area of the crystalline contribution and the total area according to equation:

$\mathrm{Cl}(\%)=\left[\left(\mathrm{l}_{002}-\mathrm{lam}\right) / \mathrm{l}_{002}\right] \times 100$

where $\mathrm{l}_{002}$ is the diffraction peak intensity of the (002) plane, $\mathrm{lam}_{\mathrm{am}}$ is the amorphous part of diffraction intensitylocated at $2 \theta$ between $18^{\circ}-19^{\circ}$.
The pyrolysis of wood $(0.05 \mathrm{mg})$ was performed with a single-shot mode pyrolyzer (PY-2020, Frontier Lab.) directly interfaced to a GC/MS system Shimadzu (QP-5000) equipped with DB - 5HT capillary column with a length of 30 $\mathrm{m} \times$ diameter of $0.250 \mathrm{~mm}$ (Agilent Technologies). The effect of catalyst was evaluated on balsa and eucalyptus only. Wood meal and catalyst powder were mixed in a 1 (balsa or eucalyptus wood) : 9 (ZSM-5) $(0.5 \mathrm{mg})$ or 1 (balsa cellulose or eucalyptus cellulose) : 9 (ZSM-5) $(0.5 \mathrm{mg})$ ratio. The interface temperature was set to $310{ }^{\circ} \mathrm{C}$. The mass spectra of samples were then compared to values in NIST library and literatures. The relative area percentage was expressed as percentages obtained by a computerized integrator based on the peak area from total ion chromatography.

The fast pyrolysis was performed by raising the temperature of pyrolyzer furnace to $600{ }^{\circ} \mathrm{C}$ without heating the sample. When the condition had stabilized, then the sample in steel sampling cup, $5 \mathrm{~mm}$ in diameter and $7 \mathrm{~mm}$ in height, was dropped to the furnace and kept at $600{ }^{\circ} \mathrm{C}$ for $0.2 \mathrm{~min}$ under the He gas flow rate of $50 \mathrm{ml} / \mathrm{min}$. The column temperature was set to $70{ }^{\circ} \mathrm{C}$ and the injection temperature was $320^{\circ} \mathrm{C}$ with a flow pressure of $1000{ }^{\circ} \mathrm{C}$ $\mathrm{kPa}$. The oven temperature was held at $90^{\circ} \mathrm{C}$ for $3 \mathrm{~min}$ and then increased up to $190{ }^{\circ} \mathrm{C}$ at $10^{\circ} \mathrm{C} / \mathrm{min}$ and kept for 5 min. The temperature increased from $190{ }^{\circ} \mathrm{C}$ to $320^{\circ} \mathrm{C}$ at $10^{\circ} \mathrm{C} / \mathrm{min}$ and isothermal at $320^{\circ} \mathrm{C}$ for $35 \mathrm{~min}$. The carrier gas used was helium with a controlled flow of $50 \mathrm{ml} / \mathrm{min}$. The data was analyzed using one way analysis of variance (ANOVA) followed by Tukey test $(p=0.05)$. All statistical calculations were conducted using SPSS-Win 16.0.

\section{Results and Discussion}

\section{Chemical Characteristics}

Table 1 shows the proximate analysis of wood of five potential fast growing species. All wood species possessed high volatile contents, on the other hand showing a low content of fixed carbon and ash content that is comparable with Meincken and Tyhoda (2014). Analysis of variance showed that there is no significant differences on the volatile matters, fixed carbon, and ash contents of jabon, sengon, and balsa. The volatile contents of jabon, sengon and balsa woods are higher than that of eucalyptus and that of rockrose wood reported by Gomez-Serrano et al. (1993). Eucalyptus wood contained lesser ash than those of jabon, sengon, and balsa woods. It is expected that slight ash content in eucalyptus wood influences on the high in yields of anhydro-sugars and high molecular furan and pyran products and also on the slight in the yield of lignin derived products such as vinyl guaiacol and syringol (Azeez et al. 2011). Strezov et al. (2007) reported that sugar pine wood containing $80.7 \%$ of volatile matter through a pyrolysis at temperature of 500 and $900{ }^{\circ} \mathrm{C}$ with a heating rate of 50 ${ }^{\circ} \mathrm{C} / \mathrm{min}$ yielded a double gaseous product than that of bagasse and macadamia nut shell containing volatile matter 
of $72.7 \%$ and $72.6 \%$, respectively. The different content of volatile matters in different wood species supposed to influence on the formation of aromatics from a catalytic fast pyrolysis process.

Table 2 shows the significant differences at 0.01 levels in the hollocellulose, a-cellulose, hemicellulose and extractive soluble in alcohol-toluene contents in jabon, sengon and balsa. Mangium dan eucalyptus woods possessed higher content of holocellulose and a-cellulose but lower content of extractive than those of jabon, sengon and balsa. In thermochemical decomposition, cellulose degraded into anhidrocellulose and levoglucosan, meanwhile hemicellulose degraded mostly into volatile matter (Mohan et al. 2006). Sharma et al. (2015) emphasized that cellulose and hemicellulose components produce more volatile and gas products, while lignin predominantly forms a charred residue. Therefore mangium and eucalyptus woods were potential to be used in fast pyrolysis for aromatic production. Jabon and balsa woods with high content of hemicellulose $30.9 \%$ and $34.6 \%$, respectively, were reasonable to yield high volatile matter contents of $92.2 \%$ and $95.0 \%$, respectively as shown in Table 1.

Table 1. Proximate analysis of the wood of five potential fast growing trees.

\begin{tabular}{lccc}
\hline & \multicolumn{3}{c}{ Proximate analysis (wt.\%, dry basis) } \\
\cline { 2 - 4 } Species & Volatile matter & Fixed carbon & Ash \\
\hline Mangium (Acacia mangium) & - & - & - \\
Ekaliptus (Eucalyptus pellita) & 82.6 & 16.94 & 0.41 \\
Jabon (Antocephalus cadamba) & 93.2 & 5.33 & 2.13 \\
Sengon (Paraserianthes mollucana) & 89.8 & 8.85 & 1.34 \\
Balsa (Ochroma sp.) & 95.0 & 3.16 & 1.85 \\
\hline
\end{tabular}

Remark: jabon, sengon and balsa showed no significantly different; (-) : not determined

Table 2. Chemical components of the wood of five potential fast growing trees

\begin{tabular}{lcccc}
\hline & \multicolumn{3}{c}{ Components analysis (wt\%, dry basis) } \\
\cline { 2 - 5 } Species & Holocellulose & a-cellulose & Hemicellulose & Extractive \\
\hline Mangium (Acacia mangium) & 87.7 & 54.7 & 33.0 & 12.1 \\
Ekaliptus (Eucalyptus pellita) & 81.8 & 56.1 & 25.7 & 11.2 \\
Jabon (Antocephalus cadamba) & $72.9^{\mathrm{a}}$ & $42.0^{\mathrm{a}}$ & $30.9^{\mathrm{b}}$ & 14.1 \\
Sengon (Paraserianthes mollucana) & $77.9^{\mathrm{b}}$ & $51.5^{\mathrm{b}}$ & $26.5^{\mathrm{a}}$ & 16.3 \\
Balsa (Ochroma sp.) & $78.4^{\mathrm{b}}$ & $43.9^{\mathrm{a}}$ & $34.6^{\mathrm{c}}$ & 14.2
\end{tabular}

Remark: values followed by the same letter on the same column are not significantly different at 0.01 level (Tukey test). Extractive soluble in alcohol-toluene.

\section{Crystallinity Characteristics}

Figure 1 shows the $X$-ray diffractogram of the wood samples studied. There are two major diffraction peaks at approximately $16^{\circ}$ and $22^{\circ}$ comparable with Poletto et al. (2012). The peak intensities differ from one species to another. The clearer difference occurred at the peak range between $21.80^{\circ}$ and $22.66^{\circ} 2 \theta$ reflection. The peak area at $21.80 \sim 22.66^{\circ} 2 \theta$ reflection follow the sequence mangium $>$ eucalyptus $>$ sengon $>$ balsa $>$ jabon, as can be seen in Figure 1.

The crystallinity of five wood using XRD varied from $26 \%$ to $41 \%$. The highest crystallinity was mangium $(41.37 \%)$, then followed by balsa (34.2\%), sengon (33.6\%), jabon (33\%), and the lowest was eucalyptus (26.2\%). The comparatively high level of lignin content along with crystalinity index in mangium wood is not expected. The reason might be due to the large amount of crystalline regions present in cellulose. In addition, these results are corresponding with Poletto et al. (2012) that the eucalyptus crystallinity was lower than other wood. The differences are influenced by the crystallite size along the crystallographic planes. The crystallinity index increased with increasing crystallite size because the crystallite surface corresponding to the amorphous cellulose region reduced (Kim et al. 2010; Poletto et al. 2012). 


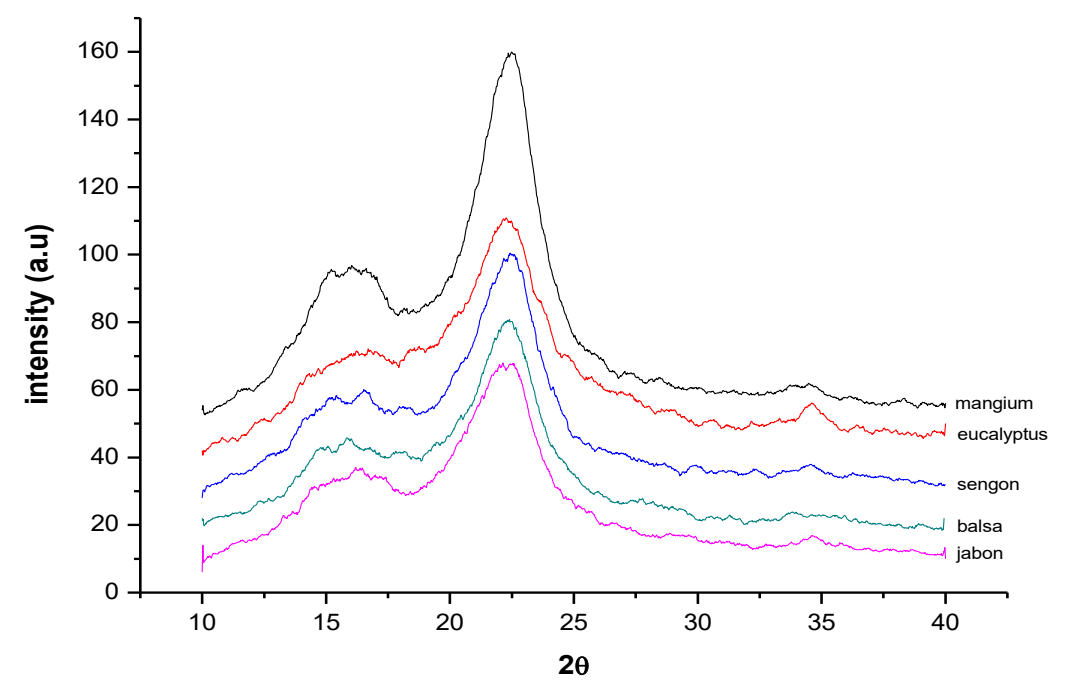

Figure 1. X-ray diffractograms of five wood species.

\section{Non-Catalytic Fast Pyrolysis}

Figure 2 display the ion chromatograms from noncatalytic fast pyrolysis of wood of the five potential fast growing species. Non-catalytic fast pyrolysis mangium, eucalyptus, balsa, jabon, and sengon woods at $600{ }^{\circ} \mathrm{C}$ formed vapours which was analyzed with GC/MS using DB $5 \mathrm{HT}$ column showing major peaks of hydroxyl acetaldehyde, furfural, guaiacol, 4-methylguaiacol, 4-vinylguaiacol, syringol, levoglucosan, vinylsyringol, and acetoyringon (Tsuge et al. 2011).

Fast pyrolysis increased the decomposition of wood through rapid and simultaneous depolymerizing and fragmenting of cellulose, hemicellulose, and lignin with rapid increase in temperature (Mohan et al. 2006). Under fast pyrolysis at $600{ }^{\circ} \mathrm{C}$, cellulose depolymerizes to miscellaneous oxygenated fragments such as hydoxyacetaldehyde, furfural, and levoglucosan, at retention time of $7.49,9.25$ and $11.97 \mathrm{~min}$, respectively. Lignin depolymerized to guaiacol, 4-methylguaiacol, 4vinylguaiacol, and syringol, at retention time of $9.73,10.3$, 10.8 and 11.2 min respectively (Shen and Gu 2009; Azeez et al. 2010; Boateng et al. 2010). The relative major peaks of chromatogram of non-catalytic fast pyrolysis are shown in Table 3. The relative peaks of levoglucosan from noncatalytic fast pyrolysis of eucalyptus wood much higher than other peaks including furfural, 4-vinylguaiacol, vinylsyringol, and acetosyringon. The high content of a-cellulose and a small content of ash in eucalyptus wood, as shown in Table 1 and 2, might influence on the high relative peak of levoglucosan, as the yield of levoglucosan is affected by the source of the cellulose (Azeez et al. 2011). The small content of ash in eucalyptus wood might also play an important role in producing a slight yield of lignin derived products such as guaiacol, 4-methylguaiacol, syringol and acetosyringon (Azeez et al. 2011). The relation of small ash content to the promoting of high yield of levoglucosan from the low crystallinity of eucalyptus wood were opposite with the previous finding that cellulose with high crystallinity degree tends to produce levoglucosan in a higher yield during cellulose pyrolysis (Wang et al. 2013; Jiang et al. 2016; Zheng et al. 2016). They reported that the cellulose with low crystallinity degree seems to have thermally decomposed through the formation of a liquid intermediate contained dehydration reactions. Meanwhile the relative major peaks were found on non-catalytic fast pyrolysis of balsa, jabon, and sengon woods. It is might be affected by high content of volatile matter which is came from cellulose and hemicellulose in these three wood species as shown in Table 1 and their high crystallinity of cellulose. 

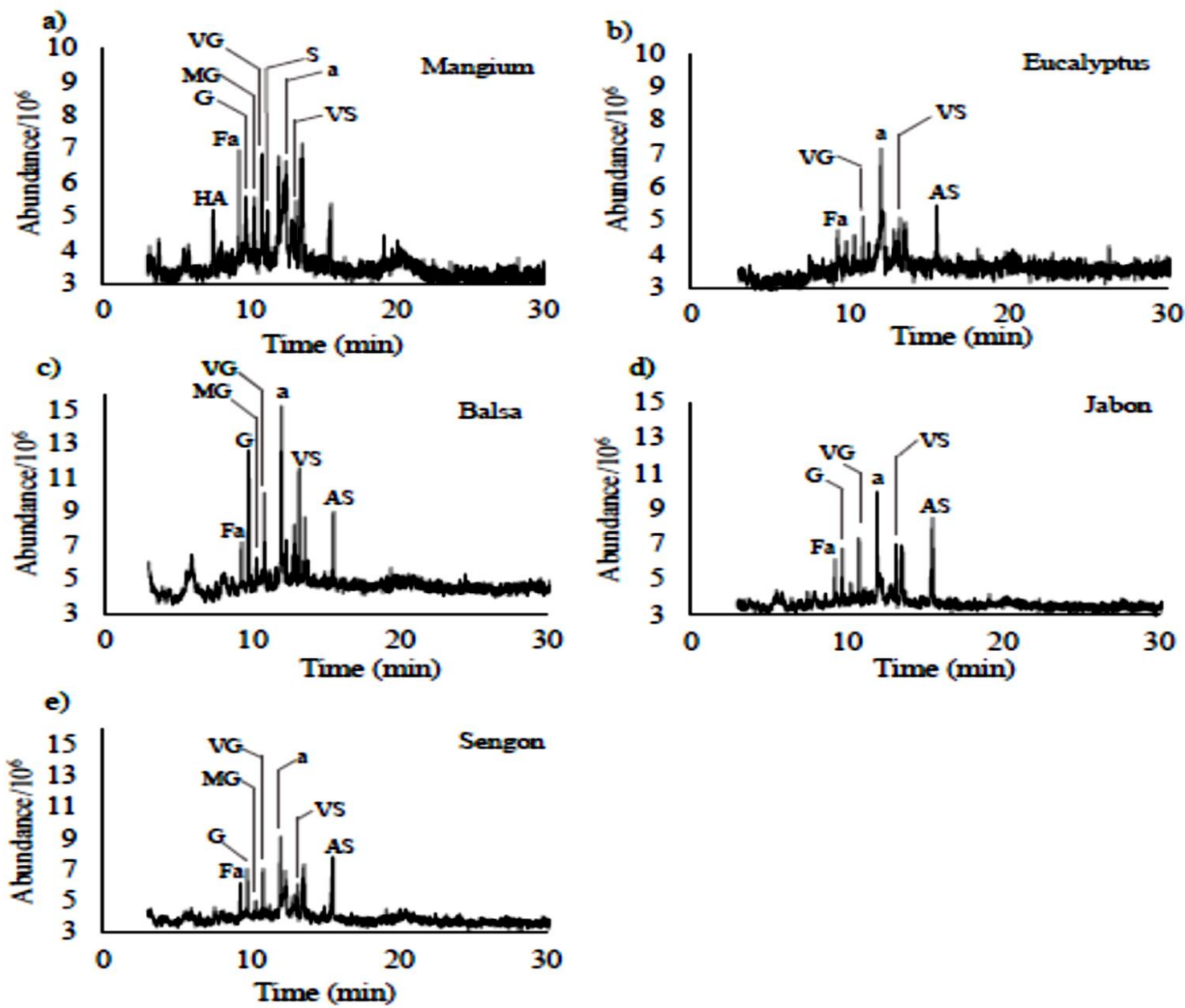

Figure 2. The ion chromatograms from non-catalytic fast pyrolysis of a) mangium, b) eucalyptus, c) balsa, d) jabon and e) sengon wood species. HA - Hydroxy acetaldehyde, Fa - Furfural, G - Guaiacol, MG - 4-Methylguaiacol, VG - 4Vinylguaiacol, S - Syringol, a - Levoglucosan, VS - Vinylsyringol, AS - Acetosyringon.

Table 3. Relative major peaks (\%) from non-catalytic fast pyrolysis of the wood of five potential fast growing trees

\begin{tabular}{rlccccc}
\hline $\mathrm{RT}(\mathrm{min})$ & Compound & Mangium & Eucalyptus & \multicolumn{1}{c}{ Balsa } & Jabon & Sengon \\
\hline 7.49 & Hydroxy acetaldehyde & 2.84 & - & - & - & - \\
9.25 & Furfural & 13.12 & 9.54 & 6.44 & 8.67 & 6.19 \\
9.73 & Guaiacol & 2.88 & - & 24.54 & 10.30 & 17.01 \\
10.30 & 4-Methylguaiacol & 4.88 & - & 1.47 & - & 0.45 \\
10.81 & 4-Vinylguaiacol & 4.18 & 7.75 & 7.79 & 0.53 & 6.22 \\
11.22 & Syringol & 2.65 & $(-)$ & - & - & - \\
11.97 & Levoglucosan & 13.95 & 70.92 & 33.65 & 16.74 & 22.60 \\
13.17 & Vinylsyringol & 16.97 & 10.58 & 11.02 & 8.40 & 10.41 \\
15.51 & Acetosyringon & - & 1.21 & 3.10 & 15.04 & 10.30 \\
& Unidentified & 38.53 & - & 11.99 & 40.32 & 26.83 \\
\hline
\end{tabular}

Remark: RT= Retention time; $(-)$ = not detected 


\section{Catalytic Fast Pyrolysis of Wood}

Figure 3 shows ion chromatogram non-catalytic and catalytic pyrolysis of eucalyptus and balsa woods. The catalytic processes in fast pyrolysis of eucalyptus and balsa wood released the aromatics peaks including benzene, toluene, styrene, $p$-xylene, o-xylene, indane, indene, and naphthalene, following the decreasing the relative peaks of oxygenated compounds such as furfural, guaiacol, 4vinylguaiacol, syringol, levoglucosan, vinylsyringol and acetosyringon (Tsuge et al. 2011; Schultz et al. 2016) as shown in Table 4. Therefore catalytic fast pyrolysis decomposed carbohydrates and lignin to produce bio-oil (Mohan et al. 2006) containing furfural, levoglucosan, guaiacol, 4-vinylguaiacol, syringol, vinylsyringol, and acetosyringon which were then diffused into ZSM- 5 pores and through a series of decarbonylation, decarboxylation, dehydration, and oligomeration reactions, aromatics were formed (Carlson et al. 2009) which were not detected on the non-catalytic fast pyrolysis of wood. ZSM- 5 catalyst with a potential ideal pore size in the range of $0.52 \sim 0.55 \mathrm{~nm}$ (Mihalcik et al. 2011) and Brönsted acid sites (Corma et al. 2009) leads to the production of aromatics in this study. The mechanism of aromatic formation from carbohydrates and lignin through a catalytic fast pyrolysis was explained elsewhere (Carlson et al. 2009; Shen and Gu 2009; Shen et al. 2010).

Relative major peaks from non-catalytic and catalytic fast pyrolysis of balsa and eucalyptus wood is shown in Table 4. There is much different between relative peaks of levoglucosan and furfural from non-catalytic and catalytic fast pyrolysis of eucalyptus wood i.e. $70.9 \sim 0.98$ and $9.54 \sim$ 1.44 , respectively. Meanwhile there is lesser different between those from non-catalytic and catalytic fast pyrolysis of balsa wood i.e. $33.6 \sim 12.6$ and $6.4 \sim 1.2$, respectively. The catalytic process in fast pyrolysis of eucalyptus decomposed the most of oxygenated compound such as levoglucosan and furfural into aromatics in the presence of ZSM-5. The potential aromatics species formed from catalytic fast pyrolysis of eucalyptus wood were including toluene, styrene, p-xylene, o-xylene, indane, indene and naphthalene. On the other hand, it was found that partly of levoglucosan and furfural generated to form aromatics in the fast pyrolysis of balsa wood. The fast pyrolysis of balsa wood released abundance volatiles as shown in Table 1, that might be intermediate species from carbohydrate vapors (Jia et al. 2017). The abundance intermediate species might cause the formation of unsaturated coke on the surface of the catalyst. The coke is formed through intermediate polymers, which ultimately decompose to unsaturated coke (Carlson et al. 2010b). The coke formation on the external surface are responsible for deactivation of zeolites, and the coke deposition within the zeolite pore reduce the capillary and diffusion flow of reactants and finally decrease the aromatic yield (Shen et al. 2015; Galadima and Muraza 2015; Rahman et al. 2018). Therefore it might require more ZSM- 5 catalyst to react with all oxygenated compounds from fast pyrolysis of balsa wood to form aromatics, as aromatics production is found as a function of catalyst to feedstock weight ratio (Carlson et al. 2010a).
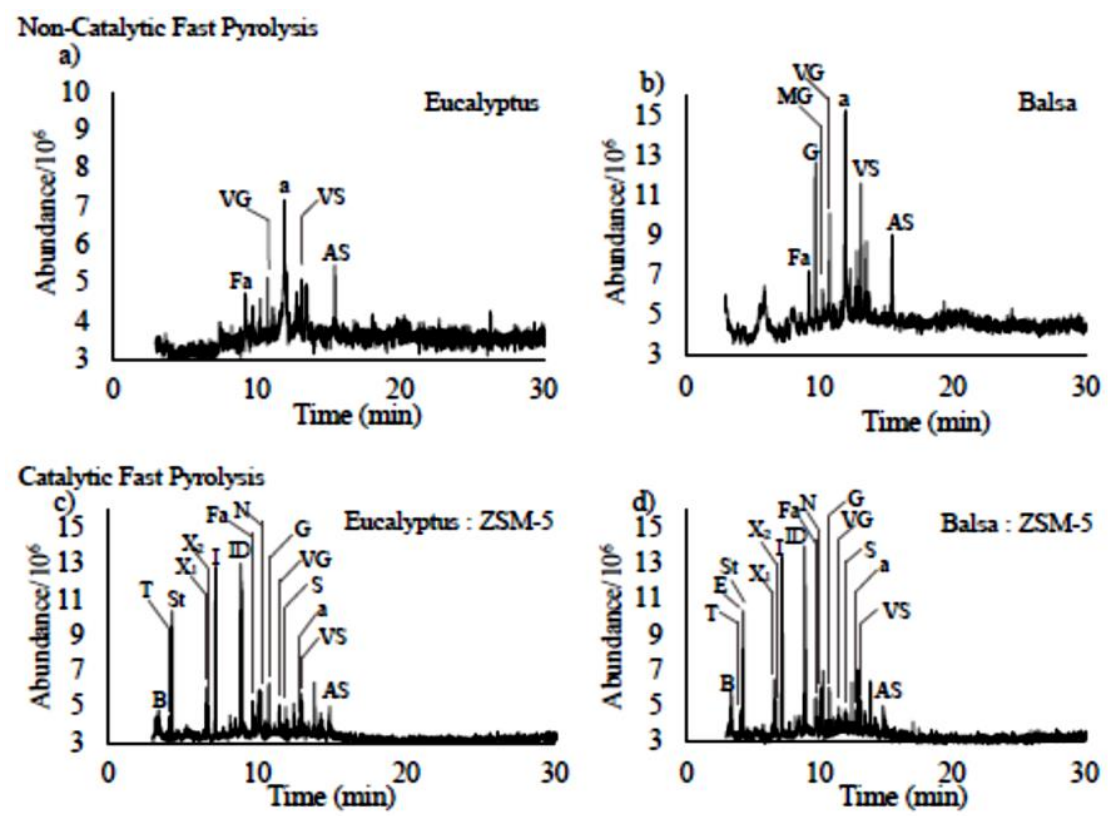

Figure 3. The ion chromatograms non-catalytic fast pyrolysis of a) eucalyptus and $b$ ) balsa woods, and catalytic fast pyrolysis of c) eucalyptus and d) balsa woods. B - Benzene, T - Toluene, St - Styrene, $X_{1}$ - P-Xylene, $X_{2}$ - O-Xylene, I Indane, ID - Indene, Fa - Furfural, N - Naphthalene, G - Guaiacol, VG - 4-Vinylguaiacol, S - Syringol, a Levoglucosan, VS - Vinylsyringol, AS - Acetosyringon. 
Table 4. Relative major peaks (\%) from non-catalytic and catalytic fast pyrolysis of balsa and eucalyptus woods.

\begin{tabular}{|c|c|c|c|c|c|c|c|c|}
\hline \multirow[b]{2}{*}{ Compound } & \multicolumn{3}{|c|}{ Balsa } & \multicolumn{5}{|c|}{ Eucalyptus } \\
\hline & $\begin{array}{c}\text { RT } \\
\text { (min) }\end{array}$ & $\begin{array}{l}\text { Non- } \\
\text { Catal. }\end{array}$ & $\begin{array}{c}\text { RT } \\
\text { (min) }\end{array}$ & Catal. & $\begin{array}{c}\text { RT } \\
\text { (min) }\end{array}$ & $\begin{array}{l}\text { Non- } \\
\text { Catal. }\end{array}$ & $\mathrm{RT}(\min )$ & Catal. \\
\hline Benzene & & - & 3.42 & 0.78 & & - & 3.40 & 0.14 \\
\hline Toluene & & - & 4.12 & 1.57 & & - & 4.12 & 1.17 \\
\hline Ethylbenzene & & - & 4.30 & 12.59 & & - & & 0.01 \\
\hline Styrene & & - & 4.31 & 11.84 & & - & 4.30 & 16.16 \\
\hline P-xylene & & - & 6.62 & 3.79 & & - & 6.62 & 4.19 \\
\hline O-Xylene & & - & 6.73 & 1.83 & & - & 6.73 & 1.46 \\
\hline Indane & & - & 7.23 & 13.43 & & - & 7.23 & 19.90 \\
\hline Indene & & - & 8.94 & 13.19 & & - & 8.98 & 21.07 \\
\hline Furfural & 9.28 & 6.44 & 9.75 & 1.23 & 9.24 & 9.54 & 9.72 & 1.44 \\
\hline Naphthalene & & - & 10.13 & 2.48 & & - & 10.17 & 2.29 \\
\hline Guaiacol & 9.76 & 24.54 & 10.80 & 0.88 & & - & 10.79 & 2.63 \\
\hline 4-Methylguaiacol & 10.30 & 1.47 & & - & & & & \\
\hline 4-Vinylguaiacol & 10.81 & 7.79 & 11.51 & 0.25 & 10.82 & 7.75 & 11.50 & 0.64 \\
\hline Syringol & & - & 11.96 & 0.25 & & - & 11.95 & 0.95 \\
\hline Levoglucosan & 11.99 & 33.65 & 12.97 & 12.62 & 11.97 & 70.92 & 12.96 & 0.98 \\
\hline Vinylsyringol & 13.18 & 11.02 & 13.17 & 0.19 & 13.17 & 10.58 & 13.03 & 0.51 \\
\hline Acetosyringon & 15.51 & 3.10 & 14.90 & 0.26 & 15.49 & 1.21 & 14.83 & 1.17 \\
\hline Unidentified & & 11.99 & & 22.81 & & - & & 25.3 \\
\hline
\end{tabular}

Remark: RT = Retention time; ( - ) = not detected

\section{Catalytic Fast Pyrolysis of Cellulose Component}

Ion chromatogram of catalytic fast pyrolysis of cellulose of eucalyptus and balsa woods is shown in Figure 4. Relative major peaks from catalytic fast pyrolysis of cellulose of eucalyptus and balsa woods are presented in Table 5. Catalytic fast pyrolysis of both celluloses of eucalyptus and balsa woods released major peaks of aromatics including benzene, styrene, p-xylene, indane, indene, and naphthalene along with the disappearing oxygenated compound derivates of cellulose i.e. furfural and levoglucosan (Tsuge et al. 2011). The catalytic process decomposed all cellulose derivates from fast pyrolysis of cellulose of eucalyptus wood to form aromatics. On the other hand, partly cellulose derivates of cellulose of balsa wood were degraded to form aromatics. As discussed previously, the formation of unsaturated coke from abundance intermediate species on the surface of ZSM- 5 catalyst influenced on the deactivation of the catalyst (Carlson et al. 2010b; Jia et al. 2017). Deactivation of ZSM5 catalyst might determine the partial degradation of cellulose of balsa wood. The abundance vapor products from fast pyrolysis of balsa wood, corresponding to the high volatile matter content of balsa wood in Table 1, might require more availability of ZSM- 5 catalyst.

Selectivity distribution of aromatics from catalytic fast pyrolysis of cellulose of eucalyptus wood from were styrene $>$ indene $>$ p-xylene $=$ indane $>$ benzene. Meanwhile cellulose of balsa wood released aromatics with the selectivity distribution was from indane $>$ indene $>$ styrene $>$ benzene $>$ p-xylene $>0$-xylene $>$ naphthalene $>$ toluene that was similar with the selectivity distribution from catalytic fast pyrolysis of balsa wood. 
Catalytic Fast Pyrolysis of Wood
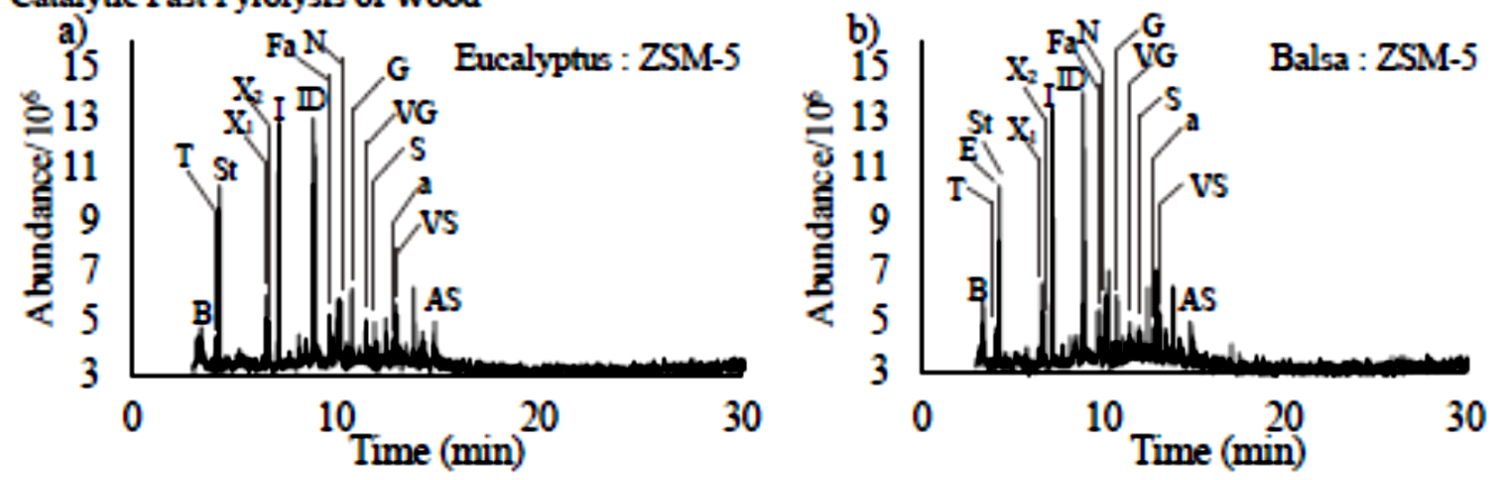

\section{Catalytic Fast Pyrolysis of Cellulose}

c)

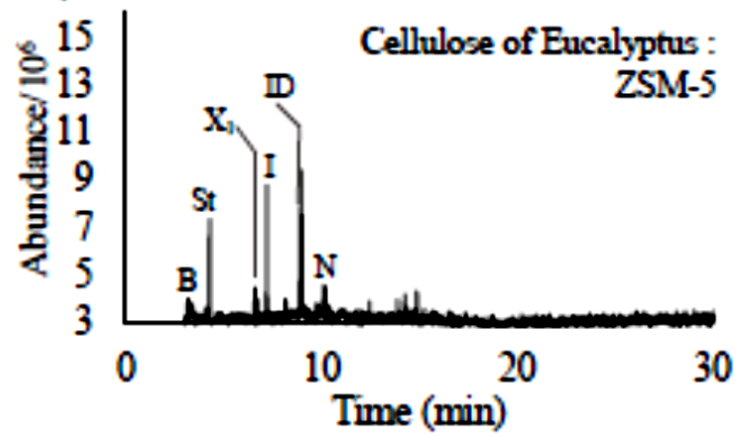

d)

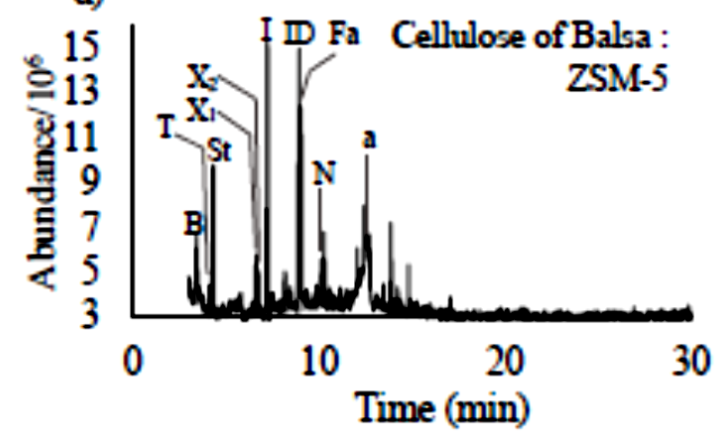

Figure 4. The ion chromatograms catalytic fast pyrolysis of a) eucalyptus and b) balsa wood, and cellulose of c) eucalyptus and d) balsa wood species. The meaning of peak is the same as that in Figure 3.

Table 5. Relative major peaks (\%) from catalytic fast pyrolysis of wood and cellulose of balsa and eucalyptus woods.

\begin{tabular}{lcccc}
\hline \multirow{2}{*}{ Compound } & \multicolumn{3}{c}{ Balsa } & \multicolumn{2}{c}{ Eucalyptus } \\
\cline { 2 - 5 } & Wood & Cellulose & Wood & Cellulose \\
\hline Benzene & 0.78 & 3.15 & 0.14 & 0.21 \\
Toluene & 1.57 & 0.95 & 1.17 & - \\
Ethylbenzene & 12.59 & - & 0.00 & - \\
Styrene & 11.84 & 10.90 & 16.16 & 24.14 \\
P-xylene & 3.79 & 2.05 & 4.19 & 2.83 \\
O-xylene & 1.83 & 1.72 & 1.46 & - \\
Indane & 13.43 & 17.65 & 19.90 & 2.83 \\
Indene & 13.19 & 13.08 & 21.07 & 11.55 \\
Furfural & 1.23 & 3.69 & 1.44 & - \\
Naphthalene & 2.48 & 1.23 & 2.29 & 6.42 \\
Guaiacol & 0.88 & - & 2.63 & - \\
4-Methylguaiacol & - & - & 0.00 & - \\
4-Vinylguaiacol & 0.25 & - & 0.64 & - \\
Syringol & 0.25 & - & 0.95 & - \\
Levoglucosan & 12.62 & 9.30 & 0.98 & - \\
Vinylsyringol & 0.19 & - & 0.51 & - \\
Acetosyringon & 0.26 & - & 1.17 & - \\
Unidentified & 22.81 & 36.28 & 25.30 & 52.02 \\
\hline Remark: (-) = not detected & & & &
\end{tabular}




\section{Conclusions}

Fast pyrolysis of eucalyptus wood characterized with low content of ash and high percentages of hollocellulose and a-cellulose produced much high relative peaks of levoglucosan followed by furfural and also small relative peaks of lignin derived products. Meanwhile high content of vollatile matter and high crystallinity of cellulose attributed balsa and jabon woods in fast pyrolysis. The catalytic processes in fast pyrolysis of eucalyptus and balsa wood released the aromatics peaks including benzene, toluene, styrene, p-xylene, o-xylene, indane, indene, and naphthalene, following the decreasing the relative peaks of oxygenated compounds such as furfural, guaiacol, 4vinylguaiacol, syringol, levoglucosan, vinylsyringol and acetosyringon. The catalytic process in fast pyrolysis of eucalyptus decomposed the most of oxygenated compound such as levoglucosan and furfural into aromatics in the presence of ZSM-5. In contrary, coke formation on the surface catalyst might cause partly of decomposition of levoglucosan and furfural to form aromatics in the catalytic fast pyrolysis of balsa wood. Cellulose component was determined on the formation of benzene, toluene, styrene, p-xylene, indane, indene, and naphthalene in catalytic fast pyrolysis of wood.

\section{Acknowledgement}

This research was carried out with support from Grant in-Aid for International Research Collaboration and Scientific Publication from Directorate General for Higher Education Ministry of Education fiscal year 2015.

\section{References}

ASTM. 1977. ASTM D1103-60. Method of test for alphacellulose in wood. Annual Book of ASTM Standards. Philadelphia.

ASTM. 1984. ASTM D1762. Standard test method for chemical analysis of wood charcoal. Annual Book of ASTM Standards. Philadelphia.

ASTM International. 2002. ASTM D1107-96. Standard test methods for ethanol-toluene solubility of wood. Annual Book of ASTM Standards. Section Four Construction Volume 04.10 Wood. Philadelphia.

ASTM International. 2004. ASTM D2866-94. Standard test method for total ash content of activated carbon. ASTM, Philadelphia.

ASTM International. 2017. ASTM D2867-17. Standard test methods for moisture in activated carbon. ASTM, Philadelphia

Azeez, A.M.; D. Meier; J. Odermatt; T. Willner. 2010. Fast pyrolysis of African and European lignocellulosic biomasses using Py-GC/MS and fluidized bed reactor. Energy and Fuels 24: 2078-2085.

Azeez, A.M.; D. Meier; J. Odermatt. 2011. Temperature dependence of fast pyrolysis volatile products from
European and African biomass. Journal of Analytical and Applied Pyrolysis 90: 81-92.Boateng, A.A.; C.A. Mullen; C.M. McMahan; M.C. Whalen; K. Cornish. 2010. Guayule (Parthenium argentatum) pyrolysis and analysis by Py-GC/MS. Journal of Analytical and Applied Pyrolysis 87: 14-23.

Bridgwater, A.V. 1996. Production of high grade fuels and chemicals from catalytic pyrolysis of biomass. Catalysis Today 29: 285-295.

Browning BL. 1967. Methods of wood chemistry. Volumes I \& II. John Wiley \& Sons. USA.

Carlson, T.R.; G.A. Tompsett; W.C. Conner; G.W. Huber. 2009. Aromatic production from catalytic fast pyrolysis of biomass-derived feedstocks. Topics in Catalysis 52: 241-252.

Carlson, T.R.; J. Jae; Y. Lin; G.A. Tompsett; Huber GW. 2010a. Catalytic fast pyrolysis of glucose with HZSM5: The combined homogeneous and heterogenous reactions. Journal of Catalysis 270: 110-124.

Carlson, T.R.; J. Jungho; L. Yu-Chuan; A.T. Geoffrey; W.H. George. 2010b. Catalytic fast pyrolysis of glucose with HZSM-5: The combined homogeneous and heterogeneous reactions. Journal of Catalysis 270: 110-124.

Corma, A.; F.J. Llopis; C. Martinez; G. Sastre; S. Valencia 2009. The benefit of multipore zeolite: Catalytic behavior of zeolites with intersecting channels of different sizes for alkylation reactions. Journal of Catalysis 268: 9-17.

Czernik, S.; A.V. Bridgwater. 2004. Overview of applications of biomass fast pyrolysis oil. Energy and Fuel 18: 590-598.

French, R.; S. Czernik. 2010. Catalytic pyrolysis of biomass for biofuels production. Fuel Processing Technology 91: 25-32.

Galadima, A.; O. Muraza 2015. In situ fast pyrolysis of biomass with zeolite catalysts for bioaromatics/gasoline production: a review. Energy Conversy Management 105: 338-354.

Gomez-Serrano, V.; C. Valenzuela-Calahorro; J. PastorVillegas 1993. Characterization of rockrose wood, char and activated carbon. Biomass and Bioenergy 4 : 355-364.

Gurgens. J.F.; M. Carrier; M.P. Garcia-Aparicio. 2014. Biomass conversion to bioenergy products. In Bioenergy from wood: Sustainable production in the tropics. Chapter 7. Ed. T. Seifert. Springer ScienceBussiness Media. Dordrecht.

Jia, L.Y.; M.Raad; S. Hamieh; J. Toufaily; T. Hamieh; M. Bettahar; G. Mauviel; M. Tarrighi; L. Pinard; A. Dufour. 2017. Catalytic fast pyrolysis of biomass: superior selectivity of hierarchical zeolites to aromatics. Green Chemistry 19: 5442-5459.

Jiang, L.Q.; A.Q. Zheng; Z.L. Zhao; F. He; H.B. Li; N.N. Wu. 2016. The comparison of obtaining fermentable sugars from cellulose by enzymatic hydrolysis and fast pyrolysis. Bioresources Technology 200: 8-13. 
Kim, S.S.; J. Kim; Y.H. Park; Y.K. Park. 2010. Pyrolysis kinetics and decomposition characteristics of pine trees. Bioresources Technology 101 : 9797-9802.

Meincken, M.; L. Tyhoda. 2014. Biomass quality. In Bioenergy from wood: Sustainable production in the tropics, Chapt. 8. Ed. Seifert T. Springer. Dordrecht.

Mihalcik, D.J., C.A. Mullen; A.A. Boateng. 2011. Screening acidic zeolites for catalytic fast pyrolysis of biomass and its components. Journal of Analytical and Applied Pyrolysis 92: 224-232.

Mohan, D.; C.U. Pittman Jr, P.H. Steele. 2006. Pyrolysis of wood/biomass for bio-oil: A critical review. Energy and Fuels 20: 848-889.

Saracoglu, E.; B.U. Basak; A.V. Esin 2017. Upgrading of fast pyrolysis bio-oil over Fe modified ZSM-5 catalyst to enhance the formation of phenolic compounds. International Journal of Hydrogen Energy 30: 1-11.

Poletto, M.; J.Z. Ademir; M.C.F. Maria; M.C.S. Ruth. 2012. Thermal decomposition of wood: Influence of wood components and cellulose crystallite size. Bioresources Technology 109 : 148-153.

Rahman, M.M., L. Ronghou, C. Junmeg. 2018. Catalytic fast pyrolysis of biomass over zeolites for high quality biooil: a review. Fuel Processing Technology 180: 32-46.

Sharma, A.; V. Pareek; D. Zhang. 2015. Biomass pyrolysis - A review of modelling, process parameters and catalytic studies renewable and sustainable. Energy Reviews 50: 1081-1096.

Schultz, E.L.; A.M. Charles; A.B. Akwasi. 2016. Aromatic hydrocarbon production from Eucalyptus urophylla pyrolysis over several metal-modified ZSM-5 catalyst. Energy Technology 4: 1-10.

Shen, D.K.; S. Gu. 2009. The mechanism for thermal decomposition of cellulose and its main products. Bioresource Technology 100: 6496-6504.

Shen, D.K.; S. Gu; A.V. Bridgwater. 2010. Study on the pyrolytic behaviour of xylan-based hemicellulose using TG-FTIR and Py-GC-FTIR. Journal of Analytical and Applied Pyrolysis 87: 199-206.

Shen, D.; J. Zhao; R. Xiao; S. Gu 2015. Production of aromatic monomers from catalytic pyrolysis of blackliquor lignin, Journal of Analytical and Appled Pyrolysis 111: 47-54.
Strezov, V.; M. Patterson; V. Zymla; K. Fisher; T.J. Evans; P.F. Nelson. 2007. Fundamental aspects of biomass carbonisation. Journal of Analytical and Applied Pyrolysis 79: 91-100.

Sulistyo, J.; T, Hata; S. Honma; R. Asakura; S.N. Marsoem. 2013. Green aromatics from catalytic fast pyrolysis of fast-growing meranti biomass. Wood Research Journal 40: 13-18.

Tsuge, S.; H. Ohtani; C. Watanabe. 2011. Pyrolysis-GC/MS data book of synthetic polymers. Pyrograms, thermograms and MS of pyrolyzates. Elsevier. UK.

Vitolo, S.; B. Bresci; M. Seggiani; M.G. Gallo. 2001. Catalytic upgrading of pyrolytic oils over HZSM-5 Zeolite: Behaviour of the catalyst when used in repeated upgrading-regenerating cycles. Fuels 80: 17-26.

Wang, Z.; A.G. McDonald; R.J. Westerhof; S.R. Kersten; C.M. Cuba-Torres; S. Ha; B. Pechad; M. GarciaPerez. 2013. Effect of cellulose crystallinity on the formation of a liquid intermediate and on product distribution during pyrolysis. Journal of Analitical and Applied Pyrolysis 100: 56-66.

Zheng, A.; L. Jiang; Z. Zhao; S. Chang; Z. Huang; K. Zhao; H. Li. 2016. Effect of hydrothermal treatment on chemical structure and pyrolysis behavior of eucalyptus wood. Energy and Fuels 30: 3057-3065.

Joko Sulistyo*, Ganis Lukmandaru, and Yunida Syafriani Department of Forest Products Technology, Faculty of Forestry, Universitas Gadjah Mada,

Jl. Agro No. 1, Bulaksumur, Yogyakarta, Indonesia

Tel. : : +62-274-6491428

Fax. : : +62-274-550541

*Email : jsulistyo@ugm.ac.id

Toshimitsu Hata

Laboratory of Innovative Humano-habitability, Research Institute for Sustainable Humanosphere,

Kyoto University, Japan.

Sensho Honma

Hokaido Forestry Research Organization Forest Products

Research Institute, Asahikawa, Hokkaido, Japan 